\title{
Antimicrobial Resistance Patterns of Salmonella Typhi Isolated from Stool Culture
}

Mohammad Atiqur Rahman ${ }^{*}$

'Department of Microbiology Jalalabad Ragib-Rabeya Medical College Sylhet, Bangladesh.

*Correspondence to:

Dr. Mohammad Atiqur Rahman Associate Professor

Department of Microbiology

Jalalabad Ragib-Rabeya Medical College

Sylhet, Bangladesh.

Mobile : +8801711195842

E-mail : atiqurrahman32@yahoo.com

http://www.banglajol.info/index.php/CMOSHMCJ

\begin{abstract}
Background: Resistance of S. typhi to a number of antibiotics has become a serious public health problem. Drug resistant S. typhi has been reported as early as 1972 in Mexico and been observed in other countries like Bangladesh, Thailand, Vietnam, Korea, Peru and India. Methods: This cross-sectional descriptive study was carried out in Ibn Sina Microbiology laboratory, Sylhet during the period from May 2012 to September 2013 to determine the antimicrobial resistance patterns of Salmonella typhi (Salmonella enterica serovar Typhi) isolated by stool culture from clinically suspected typhoid fever patients. Stool samples were collected in clean widemouthed plastic container from 249 patients, who attended Ibn Sina Hospital, irrespective of age. The specimens were cultured on Salmonella-Shigella agar (SSA), MacConkey agar (MAC) and Xylose-Lysine-Deoxycholate (XLD) Agar media. Laboratory isolation and identification of Salmonella typhi (S.typhi) were done using standard morphological and biochemical methods. Isolates identified as S typhi were differentiated from other Salmonella species using Triple Sugar Iron (TSI) agar. Antimicrobial resistance of each isolate was determined by the Modified Kirby-Bauer disc diffusion method on Muller Hinton agar using commercially available discs following Clinical and Laboratory Standards Institute (CLSI) guidelines. The panel of antimicrobials included were amikacin $(30 \mu \mathrm{g})$, azithromycin $(15 \mu \mathrm{g})$, cefixime $(5 \mu \mathrm{g})$, ceftriaxone $(30 \mu \mathrm{g})$, ciprofloxacin $(5 \mu \mathrm{g})$, chloramphenicol $(30 \mu)$, co-trimoxazole $(1.25 / 23.75 \mu \mathrm{g})$, imipenem $(10 \mu \mathrm{g})$, levofloxacin $(5 \mu \mathrm{g})$ and tetracycline $(30 \mu \mathrm{g})$. Result: Out of 249 stool specimens investigated, only 35(14.06\%) isolates of S.typhi were recovered. Among 35 positive samples $19(54.29 \%)$ were adult and $16(46.71 \%)$ were children. Antimicrobial susceptibility test showed that the resistance rates of S.typhi were $97.14 \%$ for cotrimoxazole, $95.29 \%$ for azithromycin, $91.43 \%$ for cefixime, $85.71 \%$ for tetracycline, $77.14 \%$ for ciprofloxacin and $68.57 \%$ for ceftriaxone, respectively. Increased sensitivity was reported for imipenem (88.57\%), amikacin (77.14\%), chloramphenicol (65.71\%) and levofloxacin (42.86\%). Conclusion: Of the 35 isolates of S. typhi, none was susceptible to all of the antibiotics. We therefore face the imminent prospect of encountering untreatable typhoid fever in the near future due to multi-drug resistance pattern of isolates observed in this study. Further studies with large number of specimens are highly recommended to validate the present study and to monitor microbial trends and antimicrobial resistance patterns in other parts of Bangladesh.
\end{abstract}

Key words: Salmonella enterica serovar Typhi; Typhoid fever; Multidrug resistant.

\section{INTRODUCTION}

Typhoid fever, caused by Salmonella typhi (Salmonella enterica serovar Typhi), is a global infection ${ }^{1}$. It occurs worldwide, primarily in developing nations whose sanitary conditions are poor. Typhoid fever is endemic in Asia, Africa, Latin America, the Caribbean, and Oceania, but $80 \%$ of cases come from Bangladesh, China, India, Indonesia, Laos, Nepal, Pakistan, or Vietnam² ${ }^{2}$ 
The disease remains a critical public health problem in developing countries. In 2000, it was estimated that over 21.6 million (incidence of 3.6 per 1,000 population) of typhoid occurrences world wide, resulting in 216,000 deaths and that more than $90 \%$ of this morbidity and mortality occurred in $\mathrm{Asia}^{3}$. In an urban slum in Dhaka, the incidence of Salmonella typhi (S. typhi) was found to be $390 / 100,000$ population ${ }^{4}$.

Typhoid fever is a severe and life-threatening systemic illness transmitted via the fecal-oral route and is a major cause of morbidity and mortality worldwide. It causes over 16 million new cases and over 600,000 deaths each year ${ }^{5}$. It affects only humans (who are the reservoir) and is spread through consumption of contaminated food and drink handled by people who shed the organism from stool or, less commonly, urine or water contaminated with sewage.

Resistance of S. typhi to a number of antibiotics has become a serious public health problem. Drug resistant S. typhi has been reported as early as 1972 in Mexico and been observed in other countries like Bangladesh, Thailand, Vietnam, Korea, Peru and India ${ }^{6}$.

Until the mid 1980's the first line drugs, ampicillin, chloramphenicol and co-trimoxazole (ACC) were used as standard treatment for enteric fever. Simultaneous resistance to three or more different groups of antimicrobial drugs is defined as Multidrug- Resistant (MDR) S.typhi ${ }^{7}$. Contributing factors to MDR in S. typhi may be drug misuse, drug overuse and inappropriate prescribing practices by doctors among others ${ }^{8}$. MDR S.typhi has appeared throughout the world, especially in South America, the Indian sub continent, Africa and South East Asia ${ }^{9}$.

S. typhi is one of the most resistant organisms with multi-drug resistant phenotype. ${ }^{10}$ Outbreaks of typhoid fever caused by multidrug-resistant strains pose therapeutic challenges for physicians ${ }^{11}$. While resistance to single antibiotic occurs, development of multi-drug resistance by this bacterium has complicated the health problem ${ }^{12}$.

Typhoid fever, caused by MDR S.typhi, has become a significant cause of morbidity and mortality over recent years. Due to the occurrence of drug resistant S. typhi, which is mostly due to the misuse of antibiotics by unqualified practitioners, often without laboratory support in antibiotic sensitivity test of organisms, an efficient and reliable identification and sensitivity testing is essential for proper therapy ${ }^{13}$. The present study was, therefore, undertaken to determine the antimicrobial susceptibility patterns of local isolates of S.typhi by stool culture in clinically suspected cases of typhoid fever with special reference to their multidrugresistance.

\section{MATERIALS AND METHODS}

Between May 2012 and September 2013, a total of 249 patients attending Out Patient Departments (OPDs) and admitted in Ibn Sina Hospital, Sylhet, provisionally diagnosed as having typhoid (enteric) fever were included in this study. Stool samples were collected in clean wide-mouthed plastic container from 249 patients, irrespective of age. All samples were collected using standard aseptic procedures and processed by using standard protocols.
A loopful of each stool sample was inoculated onto Salmonella-Shigella agar (SSA), MacConkey agar (MAC) and Xylose-Lysine-Deoxycholate (XLD) agar. The inoculated plates were then incubated at $37^{\circ} \mathrm{C}$ for 24 hours. Cultural and morphological characteristics of the isolates were studied thereafter and the isolates were duly identified following standard microbiological methods ${ }^{14}$. Isolates identified as S. typhi were differentiated from other Salmonella species using Triple Sugar Iron (TSI) agar ${ }^{15}$. With the aid of a sterile wire loop, a colony of S. typhi was picked and inoculated on the TSI medium in a test tube slant by first stabbing and then streaking the slope in a zigzag pattern. After incubation at $37^{\circ} \mathrm{C}$ for 24 hours, S. typhi was identified by standard laboratory methods. The test was based on the production of hydrogen sulphide $\left(\mathrm{H}_{2} \mathrm{~S}\right)$ in TSI. Antimicrobial susceptibility testing of the S.typhi isolates to various routinely used antibiotics was determined by the Modified Kirby-Bauer disc diffusion method on Muller Hinton agar (Hi-Media, Mumbai) using commercially available discs ((Hi-Media, Mumbai) following Clinical and Laboratory Standards Institute (CLSI) guidelines ${ }^{16}$. The panel of antimicrobials included were amikacin $(30 \mu \mathrm{g})$, azithromycin $(15 \mu \mathrm{g})$, cefixime $(5 \mu \mathrm{g})$, ceftriaxone $(30 \mu \mathrm{g})$, ciprofloxacin $(5 \mu \mathrm{g})$, chloramphenicol $(30 \mu \mathrm{g})$, co-trimoxazole $(1.25 / 23.75 \mu \mathrm{g})$, imipenem $(10 \mu \mathrm{g})$, levofloxacin $(5 \mu \mathrm{g})$ and tetracycline $(30 \mu \mathrm{g})$.

\section{RESULTS}

Table 1 shows the results of culture. Over a period of 17 months, 249 faecal samples were investigated for presence of S. typhi of which $35(14.06 \%)$ isolates were identified to be S. typhi. Among 35 positive samples 19(54.29\%) were adult and $16(46.71 \%)$ were children (Table-2). Table-3 outlines the resistance patterns of the isolated strains to commonly used antimicrobials. High rates of resistance against multiple antimicrobials were found in most of the isolates studied. Resistance rates were $97.14 \%$, for co-trimoxazole, $95.29 \%$ for azithromycin, $91.43 \%$ for cefixime, $85.71 \%$ for tetracycline, $77.14 \%$ for ciprofloxacin and $68.57 \%$ for ceftriaxone, respectively. Increased sensitivity was reported for imipenem (88.57\%), amikacin (77.14\%), chloramphenicol (65.71\%) and levofloxacin (42.86\%).Figure 1 and 2 shows isolated $\mathrm{S}$.typhi on XLD and SS agar media respectively.

Table 1 : Rate of culture positive and negative samples

$\begin{array}{lcc}\text { Results of culture } & \text { Number } & \text { Percentage (\%) } \\ \text { Growth of Salmonella typhi (Positive) } & 35 & 14.06 \\ \text { No Salmonella typhi isolated (Negative) } & 214 & 85.94 \\ \text { Total } & 249 & 100.00\end{array}$

Table 2 : Isolation frequency of Salmonella typhi with respect to age $(\mathrm{n}=35)$

$\begin{array}{ccc}\text { Age }(\text { Yr }) & \text { Distribution } & \text { Percentage }(\%) \\ >1-5 & 13 & 37.14 \\ >5-18 & 03 & 8.57 \\ \text { Adult } & 19 & 54.29 \\ \text { Total } & 35 & 100.00\end{array}$

$\mathrm{n}=$ Total no. of Isolates 
Table 3 : Antimicrobial resistance patterns of Salmonella typhi, Disc diffusion method $(\mathrm{n}=35)$

\begin{tabular}{llrrr} 
S.No & Antimicrobial agents & Sensitive (\%) & Intermediate (\%) & Resistant (\%) \\
1. & Amikacin & $27(77.14)$ & 0 & $8(22.86)$ \\
2. & Azithromycin & $2(5.71)$ & 0 & $33(95.29)$ \\
3. & Cefixime & $3(8.57)$ & 0 & $32(91.43)$ \\
4. & Ceftriaxone & $6(17.14)$ & $5(14.29)$ & $24(68.57)$ \\
5. & Ciprofloxacin & $4(11.43)$ & $4(11.43)$ & $27(77.14)$ \\
6. & Chloramphenicol & $23(65.71)$ & $4(11.43)$ & $8(22.86)$ \\
7. & Co-trimoxazole & $1(2.86)$ & 0 & $34(97.14)$ \\
8. & Imipenem & $31(88.57)$ & $1(2.86)$ & $3(8.57)$ \\
9. & Levofloxacin & $15(42.86)$ & $9(25.71)$ & $11(31.43)$ \\
10. & Tetracycline & $1(2.86)$ & $4(11.43)$ & $30(85.71)$ \\
\hline
\end{tabular}

$\mathrm{n}=$ Total no. of Isolates

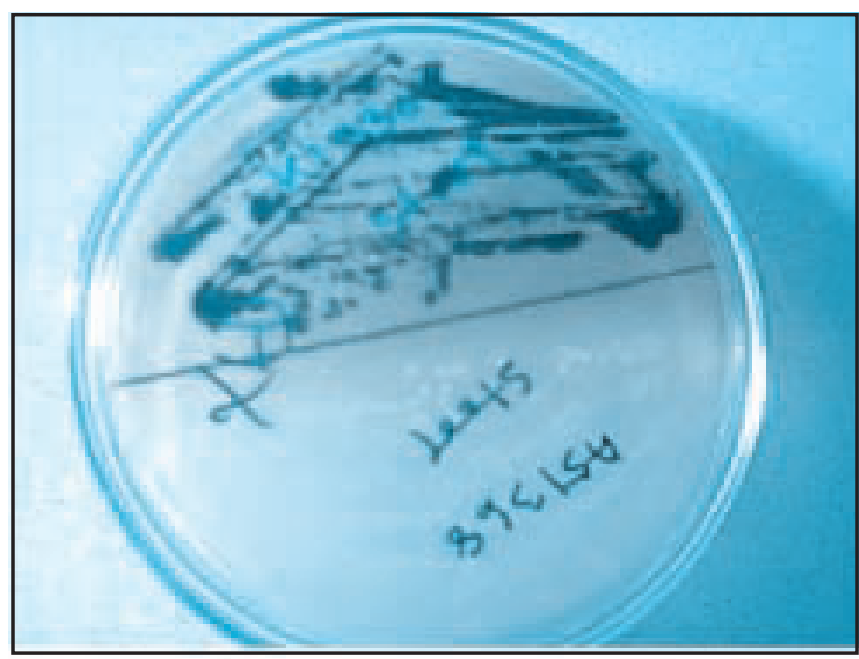

Figure 1: Salmonella typhi isolated on XLD agar

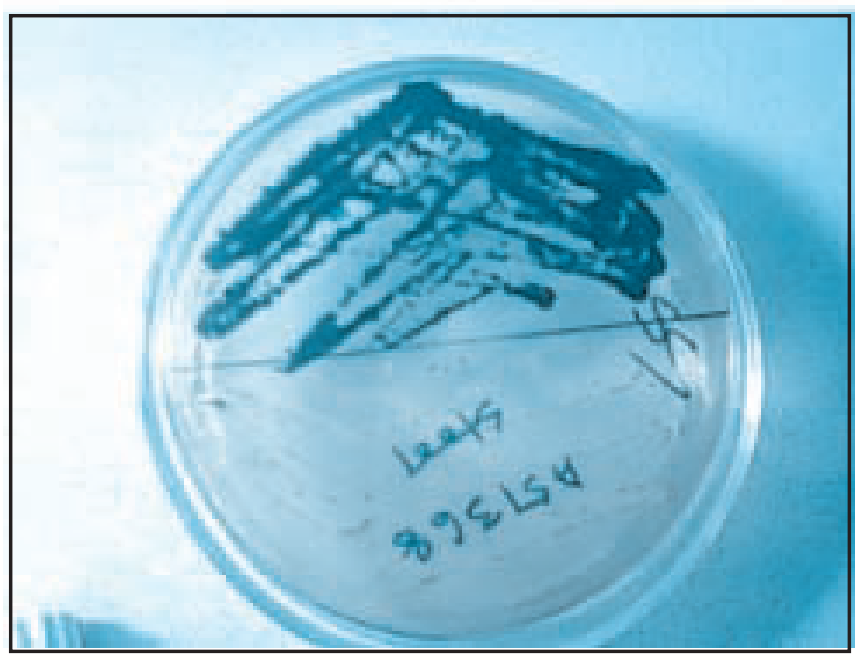

Figure 2 : Salmonella typhi isolated on SS agar

\section{DISCUSSION}

This study revealed 35(14.06\%) isolates were S. typhi, after investigating 249 stool samples from clinically suspected patients of typhoid fever. This is at variance with an earlier report by them and observed a higher incidence: 33 (31.7\%) stool samples after examining 104 samples ${ }^{17}$.

Typhoid fever may occur at any age, in this study though adults were more affected but incidence rate in children was $46.71 \%$. However, in the present study $37.14 \%$ of S. typhi isolates were in children less than 5 years of age. This finding correlates with the observation made by them and found that children between 2-3 years of age were most susceptible age group $(35.6 \%)^{18}$. Almost similar study done by them and showed $44 \%$ children were aged under 5 years ${ }^{19}$.

This study was conducted to know the antibiotic resistant patterns of S. typhi, this study reveals some relevant changing pattern in antibiotic response of Salmonella isolates.

All the salmonella isolates showed a significant decrease in susceptibility to cotrimoxazole and tetracycline. Both of antibiotics had a common sensitivity rate of only $(2.86 \%)$. Since 1989 outbreaks caused by strains of S. typhi resistant to cotrimoxazole and tetracycline have been reported in many developing countries, especially India and Bangladesh ${ }^{20,21}$.

Chloramphenicol and co-trimoxazole are part of the ACC. In this study, resistance to chloramphenicol and co-trimoxazole was seen in $22.86 \%$ and $97.14 \%$ isolates respectively. Chloramphenicol alone had a sensitivity rate of $65.71 \%$. This value is showed an increase in susceptibility of S. typhi to the ACC as reported by him ${ }^{22}$. This increase can be explained by the fact that as the ACC are not regularly used, strains that were resistant to ACC are slowly losing their resistance factors and therefore become susceptible to chloramphenicol.

In the present study, $77.14 \%$ isolates showed resistance to ciprofloxacin. Similar findings have been reported from other studies. In Bangladesh, $74 \%$ of S. typhi strains isolated with decreased ciprofloxacin susceptibility, whereas it was $50 \%$ in the United Kingdom ${ }^{23}$. Recently, MDR S. typhi strains with decreased ciprofloxacin susceptibility have been reported in India ${ }^{24}$. It may be due to the overuse of ciprofloxacin in the treatment of typhoid and in other unrelated infections. Ciprofloxacin is widely used in Bangladesh to treat many infections without prescription and is likely to result in high prevalence of resistance, limiting its utility. However only $31.43 \%$ isolates were resistant to levofloxacin in this study.

In a study in Bangladesh $94 \%$ cure rate with azithromycin was observed $^{25}$. But this study revealed $95.29 \%$ isolates were resistant to azithromycin. Azithromycin resistance apparently presents an emerging problem as treatment failures have been described $^{26}$. Azithromycin is widely used in Bangladesh due to its oral route of administration. It can be purchased over the counter of private clinics and pharmacies. It is commonly used for respiratory tract infections Over-the-counter availability of antibiotics and incomplete treatment due to many reasons in a developing country like ours may also be the factors contributing to the development of resistance. 
Alternative effective drugs available for treatment of these resistant isolates are third generation cephalosporins, ceftriaxone and cefixime, but cases of Salmonella typhi resistant to ceftriaxone have already been reported from Bangladesh, Pakistan and Philippines ${ }^{27,28,29}$. Resistance is also emerging to cefixime ${ }^{30}$. In this study, most of the strains of S. typhi isolated were resistant to drugs like cefixime (91.43\%), and ceftriaxone $(68.57 \%)$. This data is very alarming since the isolates were already showing high resistance to drugs that are meant as alternate therapy to typhoid treatment; especially isolates from stool were resistant to the commonly used antibiotics. Increased sensitivity was reported for imipenem (88.57\%), amikacin (77.14\%), chloramphenicol (65.71\%) and levofloxacin $(42.86 \%)$. Of the 35 isolates of S. typhi, not any antibiotic has complete susceptibility to the organism. We therefore face the imminent prospect of encountering untreatable typhoid fever in the near future. A national guideline on the proper usage of antibiotics is required for urgent implementation in Bangladesh.

\section{CONCLUSION AND RECOMMENDATION}

This study revealed that $\mathrm{S}$. typhi isolates are present in our clinical specimens in this area and are seriously becoming a concern due to their multi-drug resistance pattern observed in this study and urgent steps should be taken to have an evaluation principle and documented analysis of trends of occurrence of this resistant isolates to help guide in administration of less commonly resistant antimicrobials when cases occur.

The high percentage of resistance to the six antibiotics studied could be attributed to their prevailing usage and abuse in the area under study. The implication of the high percentage resistance recorded for the antibiotics is that only imipenem and amikacin will effectively treat $\mathrm{S}$.typhi infections, though some strains were resistant. Further studies with large number of specimens are highly recommended to validate the present study and to monitor microbial trends and antimicrobial resistance patterns in other parts of Bangladesh.

\section{DISCLOSURE}

The author declared no competing interest. 


\section{REFERENCES}

1. Nagshetty K, Channappa ST, Gaddad SM. Antimicrobial susceptibility of Salmonella typhi in India. Journal of Infection in Developing Countries. 2010; 4(2):070-073.

2. Chau TT, Campbell JI, Galindo CM, Van Minh Hoang N, Diep TS, Nga TT, et al. Antimicrobial drug resistance of Salmonella enterica serovar typhi in asia and molecular mechanism of reduced susceptibility to the fluoroquinolones. Antimicrob Agents Chemother. Dec 2007; 51(12):4315-4323.

3. Crump JA, Luby SP, Mintz ED. The global burden of typhoid fever.Bull World Health Organ. 2004; 82(5):346-353.

4. Brooks WA, Hossein A, Goswami D, Hahar K, Alam,K, Ahmed N, et al. Bacteremic typhoid fever in children in an urban slum, Bangladesh. Emerg Infect Dis. 2005; 11(2): 326-329.

5. Aye TT, Siriarayapon P. Typhoid Fever outbreak in Madaya Township, Mandalay Division, Myanmar. J. Med. Assoc. Thai. 2004;87:395-399.

6. Virginia V, Pato-Mesola, Manuel ES, and Donaldo: Antimicrobial susceptibility of salmonella typhi Isolates from government and private Hospitals in Cubu city. Phil J Microbiol Infect Dis. 1997; 26 (1): 5-8.

7. Rahman M, Siddique AK, Shoma S, Rashid H, Salam MA, Ahmed QS, et al. Emergence of multidrugresistant Salmonella enterica serotype Typhi with decreased ciprofloxacin susceptibility in Bangladesh. Epidemiol.Infect. 2006; 134: 433-438.

8. Ammah A., Nkuo-akenji T., Ndip R., Deas J.E., An update of concurrent malaria and typhoid fever in Cameroon. Trans-actions of the Royal Society of Tropical Medicine and Hygiene. 1999;93:127-129.

9. Gautama V, Gupta NK, Choudhary U, Arora D. Sensitivity Pattern of Salmonella serotypes in Northern India. Braz J Infect Dis. $2002 ; 6: 281-287$.

10. Keith PK, John RK. Hidden epidemic of macrolide resistant Pneumococci. Emerging Infectious Diseases. $2005 ; 11$ (6): 802 - 807.

11. Rathish KC, Chandrashekar MR, Nagesha CN. An outbreak of multidrug resistant typhoid fever in Bangalore. Indian J. Pediatr. 1995;62: 445-448.

12. Mourad AS, Metwally M, Nour El Deen A, Threlfall EJ, Rowe B, Mapes T, Hedstrom R, et al. Multiple drug-resistant Salmonella typhi. Clinical Infectious Diseases. 1993; 17: 135-136.

13. Sengupta S R. J Asso Phsycian Ind. 1991; 39: 439- 440.

14. In: Collee JG, Marmion BP, Fraser AG, Simmon A. editors, Mackie \& Mc Cartney Practical Medical Microbiology. $1996 ; 4$.

15. Reisner SB, Woods GL, Thomson RP, Larone PH, Garcia LS, Shimuzu RY. Specimen collection in: Manual of clinical microbiology. 1999;7:64-69.

16. Clinical and Laboratory Standards Institute. Performance standards for antimicrobial susceptibility testing; $18^{\text {th }}$ informational supplement.M100-S18.National Committee for Clinical Laboratory Standards. Wayne (PA): CLSI/NCCLS, (2008).

17. Ogunbiyi TA, Onabowale BO. Typhoid enteritis in Lagos, Nigeria. Nigerian Med J. 1997; 6: 505-511.

18. Saha MR, Dutta P, Palit A, Dutta D, Bhattacharya MK, Mittra U et al. A Note on Incidence of Typhoid Fever in Diverse Age Groups in Kolkata, India. Jpn. J. Infect. Dis. 2003;56: 121-122.

19. Sinha A, Sazawal S, Kumar R, Sood S, Reddaiah VP, Singh B et al. Typhoid fever in children aged less than 5 years. Lancet. 1999; 354: 734- 737 .

20. Threlfall EJ, Ward LR, Rowe B. Widespread occurrence of multiple drug-resistant Salmonella typhi in India. Eur J Clin Microbiol Infect Dis. 1992; 11:989-993.

21. Albert MJ, Haider K, Nahar S, Kibriya AK, Hossain MA. Multiresistant Salmonella typhi in Bangladesh. J Antimicrob Chemother 1991; 27: $554-555$

22. Dhanashree, B., Antibiotic susceptibility profile of salmonella enterica serovers: trend over three years showing re-emergence of chloramphenicol sensitivity and rare serovars. Indian Journal of Medicine. 2007;61:576-579.

23. Threlfall EJ, Ward LR. Decreased susceptibility to ciprofloxacin in Salmonella enterica serotype Typhi, United Kingdom. Emerg Infect Dis. 2001; 7: 448-450.

24. Chandel DS, Chaudhury R. Enteric fever treatment failures: a global concern. Emerg Infect Dis. 2001; 7:762-763.

25. Islam MN, Rahman ME, Rouf MA, Islam MN, Khaleque MA, Siddika Met al. Efficacy of azithromycin in the treatment of childhood typhoid fever. Mymensingh Med J. 2007; 16(2) :149-153

26. Molloy A, Nair S, Cooke FJ, Wain J, Farrington M First report of Salmonella enterica serotype paratyphi A azithromycin resistance leading to treatment failure. J Clin Microbiol. 2010; 48: 4655-4657.

27. Mushtaq MA. What after ciprofloxacin and ceftriaxone in treatment of Salmonella typhi. Pak J Med Sci. 2006; 22:51-54.

28. Saha SK, Talukder SY, Islam M, Saha S.A highly ceftriaxone-resistant Salmonella typhi in Bangladesh. Pediatr Infect Dis. 1999; $18: 387$.

29. Naiemi NA, Zwart B, Rijnsburger MC, Roosendaal R, Debets-Ossenkopp YJ, Mulder JA, et al. Extended-Spectrum-Beta-Lactamase Production in a Salmonella enterica Serotype Typhi Strain from the Philippines. J Clin Microbiol. 2008; 46:2794-2795.

30. Capoor MR, Nair D, Hasan AS, Aggarwal P \& Gupta, B. Narrowing therapeutic options in typhoid fever, India. Southeast Asian J Trop Med Public Health. 2006;37:1170-1174. 